BULLETIN Bulletin hispanique

HISPANIQUE Université Michel de Montaigne Bordeaux

117-2 | 2015

Métamorphose(s) : représentations et réécritures

\title{
Dedos de sutil delicadeza
}

Aracne, Ovidio y sus ecos en España

\section{Elena Cano Turrión}

\section{(2) OpenEdition \\ Journals}

Edición electrónica

URL: http://journals.openedition.org/bulletinhispanique/3989

DOI: 10.4000/bulletinhispanique.3989

ISSN: 1775-3821

Editor

Presses universitaires de Bordeaux

\section{Edición impresa}

Fecha de publicación: 15 diciembre 2015

Paginación: 485-504

ISBN: 979-10-300-0041-2

ISSN: 0007-4640

Referencia electrónica

Elena Cano Turrión, « Dedos de sutil delicadeza », Bulletin hispanique [En línea], 117-2 | 2015, Publicado

el 15 diciembre 2018, consultado el 07 mayo 2019. URL : http://journals.openedition.org/

bulletinhispanique/3989; DOI : 10.4000/bulletinhispanique.3989 


\title{
Dedos de sutil delicadeza: Aracne, Ovidio y sus ecos en Espańa
}

\author{
Elena Cano Turrión \\ Université de Cordoue
}

Létude propose un parcours à travers les formulations poétiques du mythe d'Arachné à partir de ses sources textuelles classiques, ses survivances médiévales, les traductions d'Ovide au XVI e siècle et la « Fábula de Aracne » de Lope de Vega, sans en oublier les représentations plastiques, où se côtoient " Les Fileuses » de Vélasquez et des créations de " body extreme art ".

Mots-clés : métapoétique, représentations poétiques, récréations plastiques, Arachné.

El estudio propone un recorrido por la formulación poética del mito de Aracne desde sus fuentes textuales clásicas, pasando por las pervivencias medievales, las traducciones del texto de Ovidio en el siglo XVI y la «Fábula de Aracne» de Lope de Vega; junto a recreaciones plásticas del mito donde confluyen obras como «Las hilanderas» de Velázquez o creaciones de body extreme art.

Palabras clave: metapoético, representaciones poéticas, recreaciones plásticas, Aracne.

This study offers a journey through the poetical expression of the myth of Arachne, from its classical text sources, its medieval survivals, the 16th century translations from Ovid, as well as Lope de Vega's "Fábula de Aracne», including its modelling representations, where Velasquez's Spinners meet body extreme art creations

Keywords : metapoetic, poetic representations, plastic recreations, Arachne. 


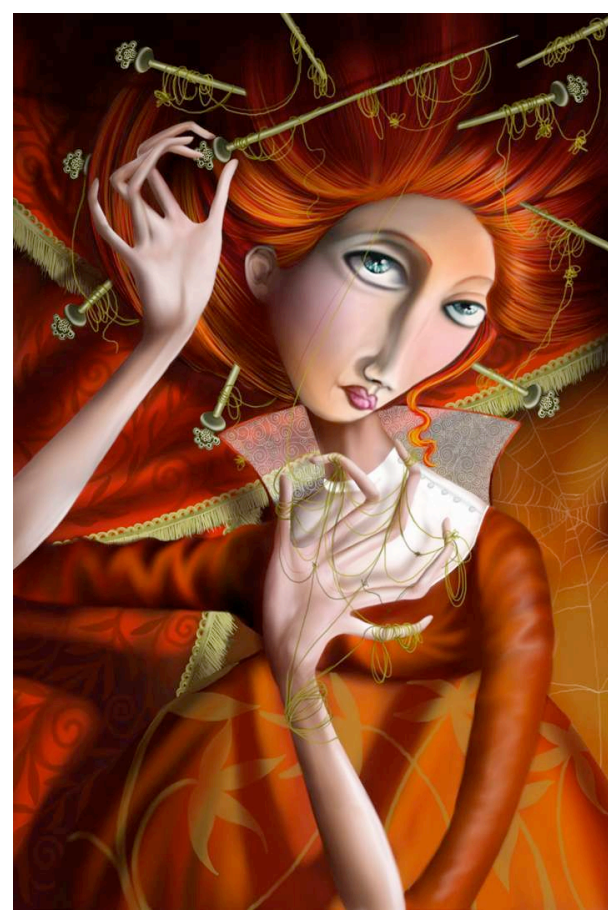

Fig. 1. - Óscar Carballo Vales, Aracne oscarcarballovales.blogspot.com

Costiene Steiner en una de sus obras que su empeño es « intentar responder $\checkmark$ a la cuestión de por qué un puñado de antiguos mitos griegos continúa dominando y dando forma vital a nuestro sentido del yo y del mundo » ${ }^{1}$. No intentaremos llegar tan lejos; no obstante, la pregunta está en la mente de todos nosotros. Una de las posibles respuestas es que los mitos, paradigmas atemporales de carácter simbólico, codifican algunos primarios enfrentamientos biológicos y sociales de la historia de la humanidad que gozan de un reconocimiento colectivo. En este trabajo trataremos el mito de Aracne dando cabida al recorrido que el mito ha realizado en el tiempo y en las diferentes disciplinas artísticas.

En la actualidad, no es extraño encontrar manifestaciones artísticas del mito en cualquier campo o disciplina. Así, entre muy diversas posiciones en varios aspectos culturales, llega hasta el videoart de la mano de la performer Noema Pascuali. La obra ${ }^{2}$, que se encuadra en la tendencia artística denominada body extreme art, muestra cómo el coser sobre el propio cuerpo (acompañado de imágenes referentes a horizontes urbanos plagados de alambres y formas muertas) simboliza el egocentrismo y la afirmación castigada de la excesiva competitividad de la protagonista, el encierro en la propia convicción que no implica su autocreación, sino el resultado de la condenación. Los choques visuales y significativos en este video nos actualizan los sistemas de reinvención de los antiguos mitos.

1. George Steiner, Antígonas. La travesía de un mito universal por la historia de Occidente, Barcelona, Gedisa, 1986, p. 13.

2. «Aracne» en http://www.youtube.com/watch ?v=DjDy-9dgqFQ [24/05/2011]. 
Otra muestra de la buena salud del mito la encontramos en el cortometraje de animación de Nich Kozis, Arachne ${ }^{3}$. Más respetuoso con la narración del mito original y mucho menos pretencioso, desarrolla la fábula en un medio completamente distinto al anterior.

Entre las ilustraciones contemporáneas del mito de Aracne, destacamos la de Dylan Meconis para Tales of Ancient Rome (2005) y la de Claudia Degliuomini para el Libro de los dioses, héroes y mitos (2005), revisión mitológica para el público infantil de Graciela Repún y Enrique Melantoni.

Estas obras constituyen una muestra de la vigencia de este personaje en la postmodernidad; no obstante, ninguna de ellas refleja con tanta exactitud el personaje original de Aracne como la obra del artista Óscar Carballo. En este dibujo digital podemos apreciar toda la potencia metafórica del mito de Aracne: la utilización predominante de tonos rojizos en su vestido, su pelo y las telas del fondo representa el orgullo desafiante que le confiere su soberbia; al tiempo, esta Aracne $^{4}$ nos es más cercana en el cambio del telar por las agujas, que clava como en un alfiletero en el ovillo enmarañado de su melena recogida; finalmente, sus habilidosos dedos largos y huesudos envueltos en telarañas parecen indicar que la transformación ya está teniendo lugar.

El siglo xx dio muestras señeras en teatro, como la obra de Adelaide Eden Phillpots Arachne, a play ; en poesía, así el poema "Arachne " de Robert Boggs o el "Arachne $»^{7}$ (1928) de Empson; y en novela, con la obra del australianolibanés David Malouf, An Imaginary Life (Una vida imaginaria, 1978) o con Die Letzte Welt (El último mundo, 1988) del escritor austríaco Christoph Ransmayr, donde Aracne ${ }^{8}$ forma parte del elenco de personajes mitológicos del pueblo en el que sitúa la trama.

En las artes plásticas, contamos con ilustraciones como las de Caselli para el libro The Illustrated Bulfinch's Mythology Legends of Charlemagne, the Age of Chivalry, the Age of Fable, 1997 o la de Susan Seddon Boulet.

El origen de este tipo de actualizaciones de los mitos se encuentra en el romanticismo y su revitalización del universo simbólico frente a la lógica de la razón y los preceptos neoclásicos. Muestras de la escasa y fosilizada realización mitológica en el Siglo de las Luces, en el que la Ilustración teñirá de

3. En http://www.youtube.com/watch?v=qW3Bbav7w4A [24/05/2011].

4. CO Óscar Carballo Vales. La obra se reproduce con autorización del autor; ésta y otras obras de este artista pueden verse en oscarcarballovales.blogspot.com

5. Adelaide Eden Phillpots, Arachne, a play, London, Cecil Palmer, 1920.

6. Robert Boggs, The Idyll of Lucinda Pearl. A Poem by..., New York, Broadway Publishing Co., 1912, p. 56-60.

7. William Empson, The Complete Poems, ed. John Haffeden, London, Allen Lane, 2000, p. 34.

8. La figura de Aracne en esta novela ha sido recientemente estudiada por Dorothée Cailleux en «Le personnage d'Arachné dans le roman Die Letzte Welt de Christoph Ransmayr ", Amaltea. Revista de mitocritica, 2010, vol. 2, p. 23-27, y junto a la obra de David Malouf, en este mismo volumen, por Nicola Kaminski en "Arachnes Netzwerke - Autorschaftsmetamorphosen bei Ovid, Malouf, Ransmayr ", p. 71-90. 
racionalismo las manifestaciones artísticas ${ }^{9}$, son las obras de Bauer, Houasse y Barbier, que reflejan estereotipadamente el mito que tratamos, las dos primeras, el momento en que Palas castiga a Aracne, y la tercera, la escena en que Palas, con todos sus atributos, se presenta a la lidia. El mito no parece tener su lugar en el siglo XVIII, apenas se registran actualizaciones literarias ${ }^{10}$ del mismo, con las excepciones, fuera de la literatura hispánica, de una versión de la historia de Aracne en la obra Liutot's Miscellany (1712) de John Gay (1685-1732), o en Friedrich Schiller, en su «Fantasie-to Laura ${ }^{11}$ y, como indica Miguel Ángel Elvira $^{12}$, parece perderse de la pintura.

Contra estas manifestaciones rígidas y sin plasticidad del mito se alzó en el siglo XIX una ilustración claramente novedosa de Aracne, el grabado realizado por Gustave Doré (1861) para el purgatorio de la Divina Comedia de Dante. Muestra el momento en que Dante, guiado por Virgilio, contempla en el purgatorio a los soberbios y sus tormentos; entre ellos, Aracne se encuentra en plena transformación, y de su cuerpo, aún de mujer, nacen a los lados las patas de la araña en que se está metamorfoseando como castigo a su soberbia, uno de los aspectos menos frecuentados en las artes plásticas.

Igualmente, reaparece el mito en los versos de Manuel José Quintana, " al fabuloso combate / en que igualar a Minerva / le costó tan caro a Aracne $»^{13}$, que se hacen eco de la contienda entre la diosa y la joven lidia; en La araña negra (1842) de Jeremias Gotthelf, seudónimo del suizo Albert Bitzius, novela en que la transformación de Aracne opera de un modo alegórico cristiano; en Arachné $^{14}$, siniestro relato de un asesino compuesto por Marcel Schwob, o en la novela escrita por el alemán George Ebers, Arachne (1898). Incluso Aracne dará su nombre al asteroide 407, descubierto por Max Wolf el 13 de octubre de 1895.

No obstante, la muestra de la vigencia del mito en la actualidad y cómo su reactualización hunde sus raíces en la reacción romántica contra las imágenes fosilizadas del Siglo de las Luces responden parcialmente al " cómo ", pero no al "por qué » de la transmisión del mito. Cada época tendrá respuestas diferentes a esta pregunta en torno a las variaciones de unos valores de la imagen mítica.

9. Según Arno Gimber « el mito fue abandonado por la Ilustración al ser considerado rudimento de épocas de superstición que no resistía a los criterios de la razón », p. 15, « Mito y mitología en el romanticismo alemán ", Amaltea. Revista de mitocrítica, 2008, n 0, p. 13-24.

10. A lo que se une su breve presencia en los escasos tratados mitográficos de la época, entre los que podemos destacar el Pantheum mythicum (1738) de Francisco Pomey que, en apenas unas líneas, resume la fábula de Aracne declarando tener su origen en las Metamorfosis de Ovidio (p. 81-82).

11. Friedrich Schiller, Poems of the first period, p. 4-6, en pdfbooks.co.za

12. Miguel Ángel Elvira, Arte y mito. Manual de iconografía clásica, Madrid, Silex, 2008, p. 210 .

13. Manuel José Quintana, Para el álbum de M.D. [Poesías] (1843-1844), ed. A. Derozier, Madrid, Castalia, 1969, p. 376.

14. En Claudio Iglesias (ed. y trad.), Antología del decadentismo, Buenos Aires, Caja Negra Editora, 2007, publicado originalmente en Coeur double (1891). 
Aracne es el orgullo desmedido por la creación propia, el enfrentamiento con los dioses, también, el artesano contra el artista, pero sobre todo, Aracne es la soberbia.

\section{OVIDIO: SIGNIFICACIÓN Y TRASCENDENCIA}

Formalizado el mito por Ovidio en sus Metamorfosis, apenas conocemos otros testimonios clásicos ${ }^{15}$ de este mito que tanto ha dado que reflexionar a pintores, escritores y artistas en general; pero comencemos por el principio.

El relato latino narra la historia de una joven lidia famosa por su arte tejiendo; lejos de la humildad, Aracne se vanagloria de tejer mejor que Palas Atenea, que pasaba por ser la inventora del arte del tejer. Al llegar a oídos de la diosa semejantes afirmaciones, ésta se disfraza de vieja y visita a Aracne en un intento de que se retracte de sus soberbias palabras, pero Aracne no rectifica y reta a la diosa a un concurso para mostrar la supremacía de su arte. Palas acepta el reto, y tejen. Mientras la diosa plasma su victoria sobre Neptuno, que dio nombre a la ciudad de Atenas (aviso amenazador del poder de Palas en sus exempla), Aracne representa una serie de episodios (los caelestia crimina, que ponen en evidencia la cuestionable moralidad de los dioses) de infidelidades de los inmortales (Júpiter con Leda, con Europa, con Danae...). La factura del tejido de Aracne ${ }^{16}$ es impecable, pero la elección de los motivos enfada a la diosa y golpea con la lanzadera a Aracne. Ésta, asustada y avergonzada, intenta

15. Virgilio: "aut invisa Minervae / laxos in foribus suspendit aranea cassit", Geórgicas IV, 246247, ed. bilingüe de J. Velázquez, Madrid, Cátedra, 1995, p. 254-257.

Plinio el viejo: "Los egipcios, los tejidos; teñir la lana, los lidios en Sardes; Closter, el hijo de Aracne, los husos en el arte de trabajar la lana; el lino y las redes, Aracne; el arte de batanar, Nicias de Mégara, y el arte de la zapatería, Tiquio de Beocia ", Naturalis Historia VII, trad. y notas de E. del Barrio Sanz, I. García Ambas, A. Ma Moure Casas, L. A. Hernández Miguel, Ma . L. Arribas Hernáez, Madrid, Gredos, 2003, p. 101-102. La referencia a Closter, hijo de Aracne, llegará al siglo XVI de manos de Ravisio Textor en su Officinae (1596) tras hacerse eco de la fábula de Aracne narrada por los poetas (columna 961).

Juvenal: "Vos lanam trahitis calasthisque peracta refertis / vellera, vos tenui praegnantem stamine fusum / Penelope melius levius torquetis Aracne ", "Sátira II ", v. 54-56, en Sátiras, trad., intro. y notas de M. Balasch, Madrid, Espasa-Calpe, 1965, p. 22.

Luciano de Samosata: "Arachné de Méonie osa provoquer Pallas Tritonie ; elle perdit sa forme et elle soccupe encore à ourdir des toiles. L'audace des humains ne peut lutter contre la colère des bienheureux, tels que Jupiter, Latone, Pallas et Pythius", Tragodopodagra en Euvres complètes, trad., intro. et notes E. Talbot, Paris, Ch. Lahure, 1857, t. II, p. 540. En relación a las representaciones plásticas, Miguel Ángel Elvira Barba, en Arte y mito. Manual de iconografía clásica (Madrid, Silex, 2008, p. 210), expone que «En la Antigüedad, el mito de Aracne sólo tiene una representación segura: la del friso del Foro Transitorio en Roma (h. 97 d. C.), dedicado a albergar un templo a Minerva erigido por Domiciano ».

16. Las diferencias entre las obras de Aracne y Palas han sido estudiadas por M. Vincent, "Between Ovid and Barthes: ekphrasis, orality, textuality in Ovid's Arachne ", Arethusa, 1994, n 27, p. 361-386; R. Di Fiore, "I colori di Aracne (Ovidio, Met. VI, 62-67) ", Aufidus, 1998, n 35, p. 41-52, y J.-P. Néraudau, "Les tapisseries de Minerve et d'Arachné (Ovide, Métamorphoses, VI, 70-128) ", L'Information littéraire, 1983, n 35, p. 83-89 (sostiene cierta reivindicación femenina contra el poder masculino de los Olímpicos). 
suicidarse; la diosa se apiada de ella, impidiendo el suicidio ${ }^{17}$, y, rociándola con el jugo de la hierba de Hécate, la convierte en araña para que teja eternamente, condenando al mismo castigo a toda su estirpe ${ }^{18}$.

Un detalle llama la atención en este relato en relación a los usos de los dioses griegos: el recurso de Palas a una hierba para la transformación de Aracne, ya que no es ni mucho menos común la utilización de magia, así podemos llamar a este detalle, por parte de los dioses. Siguiendo a Anne-Marie Tupet ${ }^{19}$, podemos establecer dos procedimientos constantes en el uso de la magia: la acción de un mago que posee esta ciencia y la utilización de instrumentos como encantaciones o fórmulas, hierbas o drogas diversas y, en ocasiones, agua y fuego. En este caso contamos con el uso de la hierba de Hécate, pero el poder de Palas presupone que no tenga necesidad alguna de estos recursos; en palabras de Tupet:

On ne trouve pas d'opérations magiques dans les mythes de Minerve; ce n'est donc pas à la déesse qu'est attachée cette pratique. Serait-ce alors à Arachné ? Nous ne connaissons aucun autre récit mettant en scène ce personnage; faut-il penser qu'une métamorphose en un insecte aussi répugnant ne pouvait s'accomplir qu'à l'aide de la magie ? C'est pure supposition, la métamorphose d'Arachné étant la seule transformation d'un être humain en insecte dans l'ouvre d'Ovide ${ }^{20}$.

Por otra parte, la metamorfosis de Aracne es casi una merced hecha por la diosa. Aracne se cuelga avergonzada por su orgullo y aterrada por la reacción de la diosa, pero ésta la salva concediéndole la vida, aunque atada a su tela como araña, como nos recuerda M. Von Albrecht:

Comment expliquer la métamorphose d'Arachné ? S'agit-il d'une punition? Mais c'est Arachné elle-même qui se pend. Elle tombe donc victime de son orgueil - qui est à la fois la plus haute et la plus dangereuse de ses qualités. Au fond, elle se punit elle-même, tandis que Pallas, qui remplace la mort par une métamorphose, lui fait plutôt une grâce ${ }^{21}$.

Al margen de si la transformación es un favor de la diosa en comparación con la muerte, la metamorfosis en araña no deja de ser un castigo; en concreto, respondería a lo que Kirk ha clasificado como " castigo por impiedad $»^{22}$, en el que se cuentan los castigos recibidos por jactarse de superar a una divinidad.

17. Para el valor cultural del suicidio, véase Ramón Andrés, Historia del suicidio en Occidente, Barcelona, Ediciones Península, 2003, p. 98.

18. Seguimos la traducción de las Metamorfosis de C. Álvarez y R. Ma Iglesias, Madrid, Cátedra, 2001, p. 385-393.

19. Anne-Marie Tupet, "La magie dans la métamorphose d'Arachné (Ovide, Met., VI, 135-145) », p. 215, Journées Ovidiennes de Parménie, Bruxelles, 1985 (coll. Latomus ; 189), p. $215-228$.

20. Ibid., p. 223-224.

21. M. Von Albrecht, "L'épisode d'Arachné dans les Métamorphoses d'Ovide », p. 271, Revue des études latines, 1980, LVII, p. 266-277.

22. Geoffrey S. Kirk, El mito. Su significado y sus funciones en la Antigüedad y otras culturas, Barcelona, Paidós, 1985, p. 186-187. 
Aunque nos ocupamos de la transmisión del mito ovidiano, no podemos dejar de reseñar un mito similar acerca de Aracne. El escoliasta de los Thēriaká de Nicandro de Colofón narra una historia etiológica con topoi de corte alejandrino sobre la transformación de dos hermanos incestuosos (Aracne y Falange) en dos tipos de araña, atribuido a un desconocido Teófilo ${ }^{23}$. De un mito muy similar da noticia el libro VI de la Mitología (Venecia, 1551) de Natale Conti:

Zenódoto contó una fábula muy distinta a éstas sobre el nacimiento de las serpientes, pues dice que hubo en la región del Ática un hombre, llamado Falange, que tuvo una hermana llamada Aracne; por lo demás, se dice que cuando Falange hubo crecido fue instruido por Palas en el arte de las armas, mientras que su hermana Aracne había aprendido muy atentamente todas las cosas que tienen que ver con la confección de las telas y el arte de coser. Pero se dice que, al haber tenido Falange relaciones con su hermana, la diosa se turbó por la fealdad de la acción y soportó la fechoría tan mal que convirtió a ambos en serpientes. Al estar grávida Aracne de su hermano, le fue ordenado por Palas que diera a luz no sin el mayor peligro de su vida, puesto que fue devorada por sus hijos, lo que se dice que también sucedió después a los demás de esta estirpe. Y algunos contaron este origen de las serpientes ${ }^{24}$.

Hay ecos en Sebastián de Covarrubias, quien tras explicar brevemente en la entrada dedicada a la palabra arańa del Tesoro ${ }^{25}$ la fábula de Aracne, en el Suplemento ${ }^{26}$, al hilo de Phalanx, parafrasea a Conti, a quien da como fuente, y añade: «Advierte que esta palabra Phalanx, entre otras significaciones, vale y es una especie de araña ponçoñosa, como Arachnes significa tanbién otro género de araña común ».

A partir del relato de Ovidio, Aracne pasa a simbolizar el pecado de hibris, a ser un aviso para navegantes de los peligros de la soberbia, y como metáfora de tal será utilizada en multitud de textos y referencias.

Dante, en La divina comedia (ca. 1315), sitúa a Aracne en el purgatorio debido a su soberbia, así dirá " ¡Oh loca Aracne, allí te contemplé, / ya medio araña, al pie de la deshecha obra que por tu mal tejida fue! $»^{27}$, recogiendo en el momento de la transformación de Aracne ante su tela destrozada por la diosa.

Ya a principios del siglo XV encontramos la historia de Aracne inserta en la obra de Cristina de Pisán, La ciudad de las damas ${ }^{28}$ (1405) donde, defendiendo

23. Cf. Álvaro Ibáńez Chacón, "La Tela de Aracne: sobre un exemplum mythologicum en La manzana de la discordia y robo de Helena de Antonio Mira de Amescua y Guillén de Castro ", Hesperia. Anuario de Filología Hispánica, 2004, VII, p. 130.

24. Natale Conti, Mitología, trad., intro., notas e índices de R. Ma Iglesias Montiel y Ma C. Álvarez Morán, Universidad de Murcia, 1988, p. 466-467. Este fragmento es una adición de la edición ampliada de 1581 y no figura en las anteriores ediciones.

25. Sebastián de Covarrubias, Tesoro de la lengua castellana o española, Madrid, Luis Sánchez, 1611, fol. $81 \mathrm{r}$.

26. Suplemento al Tesoro de la lengua española castellana, ed. G. Dopico y J. Lezra, Madrid, Polifemo, 2001, p. 237-238.

27. Dante Alighieri, La divina comedia, (vol. 2 Purgatorio), trad. Á. Crespo, Barcelona, Seix Barral, 2004, p. 139, Canto XII, v. 43-45. Compárese con el grabado de Doré citado.

28. Cristina de Pisán, La ciudad de las damas, ed. M-J. Lemarchand, Madrid, Siruela, 
el talento creativo de las mujeres, se la da por la inventora, entre otros, del arte de tejer, y a quien, cuenta la fábula, por despecho, Palas convirtió en araña. Declara Pisán cómo debemos el relato a Boccacio y su galería de mujeres ilustres $^{29}$; así, en el "Capítulo XVII. De Aragnes, la cual porque fue vencida y sobrada de Pallas en el arte de tejer, porque más sopo que ella, según dicen ahorcose ", Boccacio muestra una versión diferente de la historia, en la que Aracne se ahorca porque no soporta verse vencida por Palas, al hilo que hace una crítica a la soberbia de los hombres. Pero ya antes había tratado este tema en el capítulo tercero de la Genealogía:

Sobre la primera Minerva, primera hija del primer Júpiter [...] Sostienen que fue descubrimiento suyo el arte de la lana, desconocido antes de ella, así como el tejido, y sobre esto opina Ovidio que tuvo ésta con la colofonia Aracne un certamen sobre quién tejía mejor y obtuvo la victoria ${ }^{30}$.

El grabado con la imagen del suicidio de Aracne acompaña el relato de Cristina de Pisán ${ }^{31}$. En él no faltan los elementos propios del mito: el telar a un lado, la tela de arańa al otro y la desdichada Aracne colgando de la soga en el centro; esta elección en la ilustración del mito no será muy habitual, inclinándose la mayor parte de los artistas por el momento de la contienda de Palas y Aracne o la escena en que Palas castiga a la lidia.

Muy diferente será la imagen que presenta Francesco del Cossa en el fresco El triunfo de Minerva (1469-1470) del Palazzo Schifanoia (Ferrara). Se sitúa en el momento de la competición de Palas y Aracne, rodeadas de damas que observan sus labores, donde sólo el título de la obra nos indica que estamos contemplando la contienda de Aracne con la diosa. Igualmente plácida será la imagen que encontramos en el manuscrito holandés de La ciudad de las damas $^{32}$ de 1475 , conservado en la British Library de Londres, que refleja a Aracne tejiendo a solas con el telar.

\section{Aracne en el Siglo de Oro español}

En el período áureo las mitografías y las traducciones se encontrarán en la base del movimiento divulgativo de la mitología que se reflejará en las diferentes

2000, p. 138-139. De forma similar reaparece el mito en 1592 en la obra de Christobal Acosta Africano, Tratado en loor de las mujeres (Venecia, Iacomo Cornnetti), " Mujeres fueron principio e invención de las cosas más necesarias de la vida humana " (115v-117v), Aragne Inventora de la manera de hilar, fol. 117v-r. Cf. las referencias misóginas insertas en el poema de Lope de Vega [infra].

29. Giovanni Boccaccio, De las mujeres ilustres en romance (1374), Zaragoza, Paulo Hurus, 1494, ed. J.-L. Canet en LEMIR, en http://parnaseo.uv.es/Lemir/Textos/Mujeres/Index.html [24/05/2011].

30. Giovanni Boccaccio, Genealogía de los dioses paganos (1360), ed. Ma C. Álvarez y R. Ma Iglesias, Madrid, Editora Nacional, 1983, p. 126.

31. Cristina de Pisán, op. cit., p. 147 (fol. XXIIIv).

32. Ms. ADD 20698, fol. 90, reproducido en La ciudad de las damas, ed. cit., p. 40. 
artes. La información contenida en estas obras será claramente determinante $\mathrm{y}$, con frecuencia, será su reflejo lo que contemplemos en la poesía o las artes plásticas.

Respecto al paso del mito por las diferentes mitografías, éste suele obedecer a una exégesis moralizante; valga como ejemplo el caso de la Philosophia secreta de la gentilidad de Pérez de Moya (1585), Libro 3, capítulo 8, artículo VI « De la contienda de Palas y Aragnes »:

Esta fábula conviene a la primera Minerva, por cuanto esta contienda era sobre tejer, y la primera es a quien estos artificios se atribuyen. Otro nos da ejemplo que por más excelencia que parezca que tenemos no debemos igualarnos con Dios, ni ensoberbecernos de manera que por no reconocerlo todo de su bondad nos castigue y haga conocer lo que somos, siendo apartados de su gracia, y que todo cuanto sabemos es frágil como tela de araña, como experimentó Aragnes, vuelta en tan pequeño y vil animalejo ${ }^{33}$.

Anteriormente, el tratado de Alonso Fernández de Madrigal ${ }^{34}$, de 1507, menciona brevemente la historia de Aracne:

Dizen de Minerva que contendió con Aragne, la Colophonia, en el arte de texer, e a la fin Aragne colgósse e tornóse en araña, de lo qual larga fábula reza Ovidio, libro VI Methamorphoseos [1-145]. Esto no fue cosa alguna en la verdad, como no pudiesse muger alguna tornarse araña, mas fue puesto para significar el saber de Palas o Minerva en el arte de texer e el saber de Aragne.

En el caso de las traducciones romances del siglo XVI de las Metamorfosis, contamos con cuatro de ellas que, casi de manera general, amplifican el relato ovidiano. La primera de las ediciones, publicada anónima, se debe a Jorge de Bustamante ${ }^{35}$. En esta traducción, en prosa, el autor amplifica la fábula, respetando, no obstante, el desarrollo temático de la misma, a excepción de la acción de la hierba de Hécate y la posterior metamorfosis de Aracne:

Palas cuando vio que tan bien había tejido hubo dellos gran pesar, no porque le pareció mal, ni hubo envidia de la tela, mas porque vio los dioses en ella pintados y descubiertos sus vicios con tan grandes deshonras, por cuya causa Palas tomó luego la tela y rompióla toda porque jamás no pareciese la afrenta manifiesta de los dioses, y tomó la espada o lanzadera con que tejía y dio con ella un gran golpe en la frente de Aracne. La triste de verse menospreciada con el pesar tomando una soga se ahorcó.

33. Juan Pérez de Moya, Philosophia secreta de la gentilidad (1585), ed. C. Clavería, Madrid, Cátedra, 1995, p. 401-402.

34. Alonso Fernández de Madrigal (el Tostado), Sobre los dioses de los gentiles (1507), ed. P. Saquero Suárez-Somonte y T. González Rolán, Madrid, Ediciones Clásicas, 1995, p. 235.

35. Las Metamorphoses, o Transformaciones del muy excelente poeta Ovidio, repartidas en quince libros y traducidas al castellano. Citamos por la ed. Amberes, Juan Steelsio, 1551 (fol. 80v-85v), aunque nos consta la existencia de ediciones anteriores: s.l. n.a. (primera mitad del siglo XVI), s.l. (1546), Sevilla (1550). Cf. L. Carrasco Reija, «La traducción de Las Metamorfosis de Ovidio por Jorge de Bustamante ", en VV. AA., Humanismo y pervivencia del mundo clásico (Homenaje al profesor Luis Gil), ed. J. Ma Maestre Maestre, J. Pascual Barea, L. Charlo Brea, Universidad de Cádiz, 1997, t. II, p. 977-994. 
Palas aún hubo compasión della y alivióla sospesándola hacia arriba un poco y dijo: " ¡Malaventurada así colgada penareis de hoy más por siempre, y no moriréis quedando en ejemplo a vuestros parientes que nunca osen tomar contienda con los dioses! ". Dicho esto, Palas quitóse de allí y mudóle luego en arańa, y como era antes muy sutil, no olvidando su oficio le usa hoy día, y ésta es la causa porque aún después de convertida de su natural en tejer las telarańas es tan sutil.

La segunda traducción ( $1^{\text {a }}$ ed. Salamanca, 1580) es debida a Antonio Pérez Sigler, quien en su versión en octavas $^{36}$, deudora de la italiana de Andrea Anguillara hasta el punto de copiar las interpretaciones alegóricas de Horologgi que acompañaban dicha traducción, desarrolla en 220 versos el mito de Aracne, amplificando el original ovidiano, como en el caso anterior, pero incorporando la acción de las hierbas venenosas, sin especificar, y la transformación de Aracne:

[...] luego de hierbas venenosas / le esparce encima el zumo, y al instante / los cabellos se hundieron y narices, / una cabeza chica le quedando / igual en proporción al corpezuelo / y unos delgados brazos a los lados, / lo demás tiene el vientre de adonde echa / su estambre, y en araña transformada / ejercita el oficio que solía.

Incluye, no obstante, en la alegoría sobre el libro sexto una exégesis moralizante de la contienda de Palas y Aracne:

[...] se da a entender que no debemos por excelencia que parezca ay en nosotros, incitados de soberbia, igualarnos a Dios, porque no reconociendo venirnos todos los bienes de su bondad divina movida del justo enojo no nos haga trabucar en alguna gran miseria y apartados de su gracia vengamos a ser semejantes a tan vil animal como es la araña sin que podamos hacer cosa que no sea frágil como su tela. En el discurso de las labores de Pallas se pinta el fin a que vienen a parar los soberbios, justamente con la fábula de la insolente Niobe.

Lectura moral que llevará hasta los motivos tejidos por Aracne en su tela:

En las transformaciones de Júpiter, Neptuno y Apolo en diversos animales pintados por Aragne se dan a entender todos los efectos que el lascivo amor hace en el corazón apasionado, forzándole a usar con toda diligencia de todos los medios que le fueron posibles hasta traer a efecto a su lascivo deseo ${ }^{37}$.

Felipe Mey, en su Del Metamorfoseos de Ovidio en octava rima ${ }^{38}$ traduce, comedidamente comparado con sus predecesores, en dieciocho octavas reales la historia de Aracne y Palas, resolviendo la metamorfosis de la lidia en apenas doce versos:

Después de allí partiendo le ha esparcido / de Hécate el zumo, yerba emponzoñada, / con que nariz y orejas le han caído, / y los cabellos, luego en ser tocada, / la cabeza se le ha disminuido, / y toda su persona es abreviada. / Los dedos por extremo adelgazados / le quedaron por zancas a los lados. / Barriga es lo demás y la primera / arte ejercita agora toda vía, / del vientre saca el hilo y persevera / hecha araña en tejer como solía.

36. Metamorfoseos del excelente poeta Ovidio Nasón. Traducidos en verso suelto y octava rima con sus alegorias al final de cada libro..., Burgos, Juan Bautista Varesio, 1609 (2a ed.), fol. 131v-135v.

37. Ibid., fol. 154-155.

38. Felipe Mey, Del Metamorfoseos de Ovidio en octava rima, Tarragona, 1586, p. 297-307. 
Finalmente, Pedro Sánchez de Viana, en Las transformaciones de Ovidio ${ }^{39}$, siguiendo también la tradición de Anguillara que cita con frecuencia, alterna los tercetos en las partes narrativas, con el uso de la octava para el monólogo o el estilo directo; desarrolla en 316 versos la historia de Aracne:

Aquesto dicho Palas, apartada, / con el zumo al momento la rocía / de la hierba por Hécate hallada. / Lo cual apenas hecho, se caía / de la cabeza hermosa aquel cabello / que el oro más subido obscurecía. / Las narices y orejas caen con ello; / pequeñísima se hace su cabeza; / el cuerpo, ya gentil, dejó de sello. / Las piernas, donde estaba la belleza / que podía ser, al punto se han tornado / en dedos de sutil delicadeza, / pegados en el uno y otro lado; / y lo que de ella resta, está ocupando / el vientre, y siendo araña ha procurado / sacar materia idónea, vomitando / para sus telas el estambre y trama, / el ejercicio antiguo ejercitando. / La Lidia toda del suceso brama, / y por los frigios pueblos va volando / del caso extrańo la parlera fama.

Los " dedos de sutil delicadeza ", que dan nombre a este trabajo, son referidos a las patas de la araña, resaltando incluso en este repulsivo elemento su eficacia en el arte del tejer. En sus Anotaciones sobre el libro sexto de las transformaciones de Ovidio, añade:

Por esta fábula se da a entender que Aracne (la cual significa la humana fraude) vence y sobrepuja todas las del mundo salvo a Palas, diosa de la sabiduría. Porque el saber de dios significado por Palas conoce el engaño del hombre pues su majestad es escudriñador de los secretos corazones humanos [...]. También se puede interpretar esta fábula contra los soberbios que por alguna excelencia y ventaja que conozcan en sí, menosprecian a los demás y no reconocen tal merced de la divina mano, por lo cual movida la soberana justicia de justa indignación, les castiga con dejarles a lo cual se sigue caer luego en infinitas miserias, bastantes (si del todo no son ciegos) a darles a entender su poquedad si carecen de la gracia de dios, sin la cual no somos parte para hacer cosa intelectual, ni mecánica que no sea frágil y perecedera más que la débil tela de una arańa ${ }^{40}$.

Una de las primeras muestras en la literatura del siglo XVI, si bien italiana, aparece en la literatura pastoril; así, en la Arcadia $^{41}$ de Iacopo Sannazaro, la referencia a Aracne vendrá determinada por la tela con la que los protagonistas cazan pájaros:

[...] y allí entre dos derechos y altísimos árboles tendíamos la extensa red, tan sutil que apenas entre las hojas podía distinguirse, y que por el nombre de Aracne la conocíamos, y colocada ésta perfectamente, como es preciso, nos movíamos desde las remotas zonas del bosque [...].

39. Licenciado Sánchez de Viana, Las transformaciones de Ovidio: traducidas del verso latino en tercetos y octavas rimas por..., Valladolid, Diego Fernández de Córdoba, 1589, fol. 54v-57r. A la bibliografía que estudia esta traducción se añade recientemente el artículo de John C. Parrack, "Mythography and the Artifice of Annotation: Sánchez de Viana’s Metamorphoses (and Ovid) ", en Ovid in the age of Cervantes, ed. Frederick A. de Armas, Toronto-Buffalo-Londres, University of Toronto, 2010, p. 20-36.

40. Pedro Sánchez de Viana, op. cit., fol. 121r-121v.

41. Iacopo Sannazaro, Arcadia, ed. J. Martínez Mesanza, Madrid, Editora Nacional, 1982 (1 ${ }^{\text {a }}$ ed. 1504$)$ prosa $8^{\text {a }}$, p. 83. 
Ya en la poesía espańola del siglo XVI la referencia a Aracne tiene varios significados fuertemente lexicalizados, funcionando como metáfora de la excelencia en el arte de tejer; así en la Traducción de "Orlando furioso» de Ludovico Ariosto por Jerónimo de Urrea ${ }^{42}$; en Mexicana de Gabriel Lobo Lasso de la Vega ${ }^{43}$; en las Rimas ${ }^{44}$ de Lupercio Leonardo de Argensola, en las que, según Muñoz Torrijos ${ }^{45}:$ "El autor recurre a este mito para comparar las bellas telas tejidas por sus protagonistas, con la de su querida Dorida "; o en las de su hermano Bartolomé (1592- a.1631) ${ }^{46}$.

Como ejemplo de soberbia, aparece en las Novelas en verso de Cristóbal de Tamariz $^{47}$, referencia nacida de la écfrasis. También Cristóbal Acosta en su Tratado en loor de las mujeres y de la castidad... ${ }^{48}$, siguiendo la estela dejada por Boccaccio y Pisán, en el capítulo " Mujeres fueron principio e invención de las cosas más necesarias a la vida humana ", da a Aracne por inventora del hilar y afirma que «No menos se debe a la nombrada Aragne y a Palas, pues la primera que inventó la manera de hilar y de tejer lienzo fue Aragne de Lidia [...]. Como lo testifican Ovidio y Plinio ".

Relacionada con este tipo de referencia sobre el mito está la de Jerónimo Román, en Repúblicas del mundo: divididas en tres partes (1595):

[...] Y así cuenta Ovidio una graciosa fábula, que como hubiese una mujer llamada Aragne Colofonia y presumiese mucho de saber tejer y hacer cosas de lana y lino dijo que no había su par en el mundo, de lo cual enojada Minerva trató que se viesen, y cada una a porfía labró lo más delgado que supo y en fin la diosa venció, de lo cual desesperada Aragne se ahorcó y convirtió en araña, la cual como hoy vemos nunca hace sino hilar y tejer. Plinio hablando de esta arte y su antigüedad dice que Aragne virgen

42. Jerónimo de Urrea, Traducción de " Orlando furioso » de Ludovico Ariosto, ed. F. J. Alcántara, Barcelona, Planeta, 1988 ( $1^{\text {a }}$ ed. 1549), p. 81 « Entre lienzos entró Ruger penado, / que Aracne tales no tejió a las gentes » o "De bordar, de [coser], sabía cuanto / Aracne o Palas supieron un día ", p. 736.

43. Gabriel Lobo Lasso de la Vega, Mexicana, ed. J. Amor y Vázquez, Madrid, Atlas, 1970 ( $1^{a}$ ed. 1594), «Lleva ocupadas las robustas manos / (no en el uso de Aracne ejercitadas, / mas de Marte en reencuentros inhumanos)», p. 104.

44. Lupercio Leonardo de Argensola, Rimas, ed. J. M. Blecua, Zaragoza, CSIC, 1950, p. 42: "La tela artificiosa / de Aragne temeraria, / ni la que declaró la competencia / della i la casta diosa, / por quien dio a su contraria / por castigo tan áspera sentencia, / no tienen la excelencia, / éstas ni otra ninguna, / que mi preciosa tela ".

45. Nereida Muñoz Torrijos, «La presencia de la mitología clásica en las Rimas de Lupercio Leonardo de Argensola ", Alazet, 2002, n 14, p. 326-327.

46. Bartolomé Leonardo de Argensola, Rimas, ed. J. M. Blecua, Zaragoza, CSIC, 1951, "Camilas fuertes, que dexada el arte / de Aragne ", p. 339.

47. Cristóbal de Tamariz, Novelas en verso (1580), ed. Donald McGrady, Charlottesville, Biblioteca Siglo de Oro, 1974, "En otra horrible cueba allí siguiente / a los sentauros vio en el centro horrible, / hijos del gran Ygión, que vanamente / con Juno adúltero está en forma visible. / Y a el gran Salmeo vio, que en fuego ardiente / ymitar quiso y el tronar terrible, / y a Marsias con Apolo vio tañendo / y con Palas a Aragne contendiendo ", p. 351.

48. Cristóbal Acosta, Tratado en loor de las mujeres y de la castidad, honestidad, constancia, silencio y justicia: con otras muchas particularidades y varias historias, Venecia, Jacobo Connetti, 1592 "Mujeres fueron principio e invención de las cosas más necesarias a la vida humana ", fol. $117 \mathrm{r}-\mathrm{v}$. 
de Lydia halló la invención del hilar y dice así mesmo que halló las redes para tomar pájaros y peces y que ella halló el lino, también da esa invención a Palas o Minerva, que es lo mesmo, en lo de Palas concuerdan los poetas ${ }^{49}$.

Es frecuente también tomar la tela de Aracne como fuente de los mitos metamórficos, como en el Viaje de Sannio (1585) de Juan de la Cueva ${ }^{50}$ o un soneto incluido en la Poética silva ${ }^{51}$ (textos fechados entre 1595 y 1601).

Por otra parte, la cercanía de elementos temáticos del mito de Aracne con otros mitos produce cierta asimilación que da pie a confusiones entre ellos; es el caso del verso de Jorge de Montemayor, « ¡O!, más hermosa Nimpha mía / que Aragne parescía al su Teseo $»^{52}$, que intercambia a Aragne con Ariadne, cercanía ya documentada en Shakespeare, como comenta José Amícola ${ }^{53}$ al hilo de un análisis sobre la cadena de influencias literarias presentes en Roberto Arlt, Julio Cortázar y Manuel Puig.

También en la emblemática tendrá lugar la representación soslayada del mito de Aracne. Así, en la obra de Juan de Borja ${ }^{54}$, encontraremos el emblema «Funiculi vanitatum » (Los lazos de la vanidad):

De los vanos, que hacen sus obras, siguiendo la vanidad, y la miseria del mundo, y de todo lo que en él se contiene, se dice que labran lazos, y cuerdas de vanidad, tan sutiles, $\mathrm{y}$ tan inútiles, como son las telas, que las arañas hacen...

En el que, como analiza Julia D’Onofrio, « La idea de vanidad, por supuesto que se liga al mito de Aracne, la eximia tejedora tan confiada en su arte, que se animó con soberbia a competir con Palas ${ }^{55}$. Similar asociación se encuentra

49. Jerónimo Román, Repúblicas del mundo, divididas en tres partes, Salamanca, Juan Fernández, 1595, Libro nono « De la antigüedad del lino, de la lana, del modo de hilarlo y texerlo, y quando fue hallada la seda, y las colores para teñir los paños ", cap. XI, fol. 380r-380v.

50. Juan de la Cueva, Viaje de Sannio, J. Cebrián, Madrid, Miraguano, 1990, p. 67, " No cometiste sólo este delito / en forma transformándote fingida, / qu'en delfín i en bezerro hallo escrito / bolverse tu figura conocida; / a la tela de Aragne me remito / donde tu istoria al vivo fue esculpida, / que de vergüença de dezir quien eres / callo el engaño de Medusa i Ceres ».

51. Poética silva, ed. I. Osuna, Sevilla, Universidad, 2000, t. I, « Deje Apolo los brazos avarientos / de su avarienta y fugitiva dama, / que aun convertidos en hojosa rama / satisfacen sus vanos pensamientos, / deje Adonis los gustos y contentos / de la gallarda diosa que le ama, / Júpiter deje cuantos en su trama / puso Aragne gozando por momentos, / que es aire su placer y sus abrazos, / pues unos vide yo que en solo vellos / sobrepujé la gloria de sus lazos. / Dueño de mi alma y de estos brazos bellos, / haz que me sean de favor tus brazos, / y subiré a tu cielo puesto en ellos ", p. 244.

52. Jorge de Montemayor, Cancionero (1554-1559), ed. J. B. Avalle-Arce y E. Blanco, Madrid, Turner, 1996, p. 683.

53. José Amícola, «El hilo de Arachné y la toma de distancia », p. 167, Revista Iberoamericana, enero-marzo 2000, vol. LXVI, n 190, p. 163-174.

54. Juan de Borja, Empresas morales de don Juan de Borja, Bruselas, Francisco Floppens, 1680 [2a ed. que aumenta la original de 1581 con 124 emblemas que habían quedado manuscritos], su nieto publica en Bruselas otras 124 empresas que habían quedado manuscritas. Ambas ediciones pueden consultarse en http://www.archive.org.

55. Julia d'Onofrio, «"En cárcel hecha por su mano”. Rastros de la emblemática en El celoso extremeño de Cervantes ", Bulletin of the Cervantes Society of America, 2008, vol. 28, p. 19-40. 
en la empresa 37 de Francisco de Villaba ${ }^{56}$, en la que la figura de la araña se tiñe con los conceptos de ambición y artificio.

A principios del siglo XVII, las referencias poéticas españolas se mantienen en el tono del siglo anterior, y seguimos viendo su utilización referida al arte de tejer, así en El viaje entretenido ${ }^{57}$ (1603), en la Vida, excelencias y muerte del gloriosísimo patriarca San Jose ${ }^{8}$ (1604) de José de Valdivieso, en los Discursos, epistolas y epigramas de Artemidoro ${ }^{59}$ (1605) de Andrés de Rey de Artieda, La Atalanta. Comedia en tres jornadas (1616) de Gaspar de Ovando ${ }^{60}$ o la utilizada en 1624 por Bernardo de Balbuena para alabar los vellones de Segovia ${ }^{61}$.

Se cita, también, la fábula de Aracne para simbolizar la soberbia, la absurda lucha de alguien inferior con otro claramente superior; así sucede en la tercera parte de El Criticón (1657), "En el invierno de la vejez » ${ }^{62}$, o en la comparación realizada por Faria y Sousa respecto a Góngora y Camoens, recogida en el Apologético $^{63}$ (1662), aunque también como referencia meramente testimonial del mito la del Triunfo parténico ${ }^{64}$ (1683).

En la pintura del siglo XVI, diversas obras ilustran algunas escenas del

56. Francisco de Villaba, Empresas espirituales y morales, Baeza, Fernando Díaz de Montoya, 1613, $2^{\text {a }}$ parte, p. 71.

57. Agustín de Rojas Villadrando, El viaje entretenido, ed. J. Joset, Madrid, Espasa-Calpe, 1977, «Aragne inventó el hilar, Safo el hacer versos », p. 230.

58. José de Valdivieso, Vida, excelencias y muerte del gloriosísimo patriarca San José, C. Rosell, Madrid, Rivadeneyra, 1854, "Hace Josef que la madera cruja, / Quejosa de la sierra que la ofende; / Su Esposa diestra en la sutil aguja / El blanco lienzo con destreza hiende; / Labrando en él con tal primor dibuja, / Que Minerva admirada della aprende, / Y atenta mas que con Aragne brava / Su gracia admira y su labor alaba ", Real Academia Espańola : Banco de datos (CORDE) [en línea]. Corpus diacrónico del español. http://www.rae.es [8/01/2011].

59. Andrés de Rey de Artieda, Discursos, epistolas y epigramas de Artemidoro, ed. A. Vilanova, Barcelona, Selecciones Bibliófilos, 1955, "Circ. El que sacarle de mis manos piensa, / offrecida una vez su fe y palabra, / la rueda de Exión terná suspensa / y acabará la red que Aragne labra. / Imposible es a Circe hazerle offensa / sin que la tierra se estremezca y abra ", p. 109.

60. Gaspar de Ovando, La Atalanta. Comedia en tres jornadas (1616), ed. M. J. Franco Durán, Kassel, Reichenberger, 2001, « en una cuadra abrigada, / de ricos curiosos paños, / que de seda y oro Aracne / tejió con soberbia a mano ", p. 104-105.

61. Bernardo de Balbuena, El Bernardo, ed. C. Rosell, Madrid, Imp. Rivadeneira, 1851, «Esta es Segovia, donde la fineza / De Aragne en sus vellones mas se apura; / Y aquella la real puente de Trajano, / Y el Balsahin ó paraíso humano », p. 317.

62. Baltasar Gracián, El Criticón, "En el invierno de la vejez », ed. M. Romera-Navarro, Philadelphia, Pennsylvannia Press, 1940, «Y assí veréis que los ignorantes se lo beben, los lisongeros lo aplauden y los sabios no osan chistar, con que triunfa Aragne contra Palas, Marsias contra Apolo, y passa la necedad por sutileza y la ignorancia por sabiduría », p. 154.

63. Juan de Espinosa Medrano, Apologético en favor de don Luis de Góngora (1662, Perú), ed. V. García Calderón, Paris, Revue Hispanique, 1925, dice que es como "contender Aracne con Palas, Marsias con Apolo, y la Mosca con el Águila ", p. 529.

64. Carlos Sigüenza y Córdoba, Triunfo parténico (México, 1683), ed. J. Rojas Garcidueñas, Xochitl (México), 1945, «y más viéndose allí verificada de nuevo la historia mitológica de la presumida Aracne, pues cuando quizá se esforzaba más para emular en sus bordados tan compartidas labores, quedó pendiente del techo transformada no en una, sino en diversas arańas que sobre la plata de su materia dieron lugar a crecidísimo número de bujías con que se le aumentaban a aquel espacio sus lucimientos ", p. 97. 
mito, mayoritariamente las escenas de la contienda en el telar o el castigo de Palas a Aracne, así en los frescos de Tadeo Zuccari para el Palazzo Farnese de Caprarola (1563-1564) y de Luca Cambiaso para el Palazzo Doria de Genova, respectivamente. No obstante, ninguna con la potencia metafórica de la obra de Paolo Caliari (el Veronés) del Palazzo Ducale de Venecia (1575-1578), en la que Aracne contempla sobre ella la tela en la que se verá atrapada para siempre. Al tiempo, no podemos dejar de mencionar la obra de Jacopo Robusti (Tintoretto) situada en la Galería de los Uffizi de Florencia, si bien, temáticamente, repite la escena de la diosa y la lidia ante el telar ya tan conocida.

Diversas obras pictóricas del siglo XVII ilustran la escena de Palas agrediendo a Aracne, entre ellas Minerva y Aracne (1636) de Rubens (Richmond, The Virginia Museum of Fine Arts) o Aracne y Minerva (1695) de Luca Giordano (El Escorial), que llega estereotipada al siglo XVIII, como comentábamos al principio.

El caso de Las hilanderas (Museo del Prado de Madrid) de Velázquez merece que nos detengamos brevemente. Durante mucho tiempo se creyó que esta obra era debida al naturalismo fotográfico de Velázquez, quien, como aposentador, visitó con unas damas la fábrica de tapices de Santa Isabel y decidió inmortalizar tan bella imagen ${ }^{65}$. El primer plano de la obra representa a dos hilanderas, la de la derecha, de espaldas al espectador y la de la izquierda sujetando en su mano izquierda el hilo de un huso; tras ellas, otras tres jóvenes ayudan a las hilanderas. En el segundo plano, tras unos escalones, hay una escena más iluminada en que tres elegantes damas contemplan un tapiz que representa el rapto de Europa; entre el tapiz y las damas, Palas alza el brazo para castigar a Aracne. La crítica ha interpretado el esquema compositivo como representación de la oposición entre el arte (la pintura, simbolizada en el tapiz) frente al trabajo manual (las hilanderas), separando ambos niveles con unos escalones muy altos, que subrayarían la dificultad de pasar de un nivel a otro. Aparece además, como una pista para identificar la fábula de Aracne, la viola, ya que, como dice Diego Angulo ${ }^{66}$, se trata de uno de los instrumentos cuyo sonido curaba, según las creencias de la época, la picadura de araña.

Sin embargo, Lorenzo Martín del Burgo ${ }^{67}$ propone otra visión. No hay dudas de la representación de la fábula de Aracne en segundo plano; no obstante, la escena en primer plano no se encuentra igual de esclarecida y se revela como fundamental para la comprensión global de la obra. Ya Angulo vio cómo el movimiento de las hilanderas copia el de los gnudi de la Capilla Sixtina de Miguel Ángel, sin dudas a este respecto, pero la hilandera de la izquierda, tradicionalmente considerada de avanzada edad, se revela para

65. Cf. Ricardo Sanmartín, "Velázquez y Aracne, el mito y la época ", Éndoxa. Series Filosóficas, Madrid, UNED, 2003, n 17, p. 183-206.

66. Diego Angulo, "Velázquez, cómo compuso sus principales cuadros ", 1999, cit. por R. Sanmartín, art. cit., p. 204.

67. Lorenzo Martín del Burgo, «De nuevo sobre el significado iconográfico de Las hilanderas de Velázquez: ¿fábula de Aracne o Penélope hilando? ", Arbor, enero-febrero 2006, CLXXXII, $\mathrm{n}^{\circ} 717$, p. $17-25$. 
Martín del Burgo como otro de los personajes más conocidos de la mitología: Penélope. Así contemplamos la juventud de la pierna que muestra, al igual que su rostro, al tiempo que, al recordar la descripción de Penélope en la Odisea, la recordamos velada, igual que nuestra hilandera. Si esto no fuese suficiente para plantear serias dudas al respecto de la interpretación, recuerda que Velázquez basaba la composición de sus creaciones en modelos previos de pintores anteriores, y en este caso el origen de la composición general del cuadro se encuentra en la obra "Penélope tejiendo " del pintor italo-flamenco Giovanni Stradano-Jan van der Straat, pintada para decorar las habitaciones de Leonor de Toledo, hija del virrey de Nápoles don Pedro de Toledo y casada con el gran duque de Toscana, Cosme de Médicis, en el Palazzo Vecchio de Florencia. La obra, circular, se divide en dos planos, en el primero Penélope se encuentra trabajando en el torno, en el segundo, rodeada de sus sirvientas trabaja en el telar. La contraposición de ambos mitos no es nueva: son ambas tejedoras, pero una protegida, debido a su castidad, y la otra castigada, a causa de su soberbia, por Palas; a la luz de esta interpretación del primer plano del cuadro, el sentido global de la obra sería el poder de Palas, que protege o castiga.

Este recorrido áureo del mito muestra el amplio conocimiento de la fábula de Aracne por poetas y pintores, quienes, más en la poesía que en la pintura, hacen un uso rígido y estereotipado del mito. Por otra parte, nos resulta extraño que el siglo de las fábulas mitológicas por excelencia no haya dejado varias muestras de ello al respecto del mito de Aracne. Sin embargo, así es, y no encontramos ninguna fábula de Aracne exenta como las muchas dedicadas a otros tantos mitos.

\section{La fábula de Aracne de Lope de Vega}

A pesar de las múltiples alusiones a Aracne en la poesía española del siglo XVI, no encontramos ninguna fábula mitológica que desarrolle dicho mito, a excepción de la inserta por Lope de Vega en La Arcadia ${ }^{68}$ (1598). Esta obra, como recuerda Antonio Sánchez Jiménez ${ }^{69}$, fue de los libros más leídos y admirados durante el siglo XVII; junto al Isidro, en quintillas, y la Dragontea, constituyen el intento del Fénix de cambiar su imagen de autor de comedias y romances por la de autor erudito y respetado.

Resume Lope en doce quintillas el mito de Aracne, comenzando por la rabia que la diosa siente al ver la fama adquirida por ésta en el arte de tejer, y por su intento, convertida en vieja, de hacerla desistir de su osadía. La tercera quintilla ("Viendo que la menosprecia, / vuelve a ser lo que solía, / y tanto Aragnes porfía / que mostró ser hembra y necia / en que a Palas desafía ») desarrolla un tópico ajeno al mito original pero muy extendido en la época; luego volveremos

68. Lope de Vega, La Arcadia, ed. Edwin S. Morby, Madrid, Castalia, 1975, p. 150-155 [fábula desde 152].

69. Lope de Vega, El Isidro, ed. Antonio Sánchez Jiménez, Madrid, Cátedra, 2010, p. 18-19. 
con él. En las siguientes siete quintillas, el Fénix despliega toda su erudición para poetizar los motivos de las telas de Palas y Aracne, resolviendo el final de Aracne en las dos quintillas finales; la penúltima da cuenta del golpe propinado por Palas a Aracne con la lanzadera y, finalmente, la última cómo la transforma en araña ("Vuélvela araña tardía, / ponzoña la sangre fría, / sin escucharle palabra, / donde agora cuelga y labra; / que, como es mujer, porfía "). Obvia Lope el intento de suicidio de Aracne, al tiempo que vuelve a introducir, al final, comentarios misóginos.

¿Es Lope un autor misógino? No parece, a la luz de sus propias vivencias, que Lope profesase ningún tipo de odio hacia las mujeres; no obstante, pueden desprenderse de su obra varias consideraciones al respecto.

En principio, la tendencia misógina se remonta a tiempos muy lejanos. Distinguimos dos ramas que se juntarán en la Edad Media, la tradición misógina judeo-cristiana que arranca en la $\mathrm{Biblia}^{70}$, pasando por la Patrística ${ }^{71}$, y la que parte de la antigüedad grecolatina con textos ilustres como la sátira VII Contra femina de Juvenal, o los múltiples comentarios de Platón y Aristóteles. Pero el período fundacional de la misoginia en la cultura hispánica es sin duda la baja Edad Media, donde, como explica Anna Caballé $^{72}$, la tendencia misógina se intensifica y recrudece.

Los textos misóginos en esta época son legión, excede el propósito de nuestro trabajo detenernos en tanto teólogo, moralista y poeta así, como dice David J. Viera, «La mayoría de los escritores didáctico-morales y satírico-misóginos de Iberia concordaron en que la mujer es avara, codiciosa, celosa, inconstante, habladora, jactanciosa, porfiada, engañosa, rebelde, etc. $»^{73}$. Incluso en el Renacimiento, "Erasmo o Vives seguían viendo en ella al enemigo natural del hombre y el mayor escollo en el camino de la salvación eterna $»^{74}$. No obstante, nos interesa un texto en particular por su trascendencia en Lope de

70. " no hay veneno como veneno de mujer, / ni furia como furia de enemigo. / Prefiero convivir con león o dragón / a convivir con mujer mala. / [...] Toda malicia es poca junto a la malicia de mujer, / ¡que la suerte del pecador caiga sobre ella! / Cuesta arenosa bajo los pies de un viejo, / así es la mujer habladora de un marido pacífico. / No te dejes llevar por belleza de mujer, / por mujer no te apasiones. / Blanco de ira, de deshonra y gran vergüenza, / eso es la mujer que mantiene a su marido. / Corazón abatido, rostro sombrío, / herida del corazón, eso es la mujer mala. / Por la mujer fue el comienzo del pecado, / y por causa de ella morimos todos ", Eclesiástico 25, 22-23, cit. en p. 279-280 por J. Adrián Escudero, "Cristina de Pizán y la sinrazón de la misoginia ", Diálogo filosófico, 2004, n 59 , p. 275-294.

71. Entre otros muchos, san Jerónimo, Contra Joviniano, insiste en la virginidad como ideal de perfección en la mujer, y cita un pasaje misógino que afirma haber sacado de una obra, por otra parte desconocida, De nuptiis, que atribuye a Teofrasto. Cf. Robert Archer, Misoginia y defensa de las mujeres. Antología de textos medievales, Madrid, Cátedra, 2001, p. 22.

72. Anna Caballé, Una breve historia de la misoginia, Barcelone, Lumen, 2006, p. 58.

73. David J. Viera, "El hombre cuerdo no debe fiar de la mujer ningún secreto" como tema de la literatura clásica hispánica ", Thesaurus, t. XXX, n 3, 1975, p. 557.

74. Ma Teresa Cacho, "Misoginia y barroco: Baltasar Gracián », Literatura y vida cotidiana, ed. Ma Ángeles Durán y José Antonio Rey, Zaragoza, Servicio de Publicaciones de la Universidad Autónoma de Madrid / Secretariado de Publicaciones de la Universidad de Zaragoza, 1987, p. 175 . 
Vega, nos referimos al Examen de ingenios para las ciencias (1575) del doctor Juan Huarte de San Juan, donde se infiere la incapacidad de la mujer para las obras de ingenio. Sirviéndose de este texto, Lope escribió la comedia $\mathrm{La}$ prueba de los ingenios (1618), incluida en la novena parte de su teatro, en la que la protagonista compite en inteligencia y sabiduría con oponentes masculinos saliendo vencedora ${ }^{75}$ : en ella el debate sirve para presentar los argumentos misóginos de la época y su refutación.

Por otra parte, Lope defiende a las damas cultas en otros textos ${ }^{76}$, e incluye, como sabemos, a varias poetisas en su famoso Laurel de Apolo (1630). Sin embargo, muchos son los ejemplos que se pueden extraer de la obra de Lope en los que se ataca a las mujeres. Así en La dama boba (1613), acto I, " ¿para qué quiero yo que, bachillera, / la que es propia mujer conceptos diga? " 77 , "Demás de esto, las mujeres / naturaleza tenemos / tan pronta para fingir / o con amor o con miedo, / que, antes de nacer, fingimos $»^{78}$, la definición de una buena mujer en Períbáñez y el comendador de Ocaña (1614), acto I; o los comentarios de sus personajes en las Novelas a Marcia Leonarda (1621-1624) sobre la mujer como interesada, que se consuela rápido de los males de amores, vengativa, engańosa, etc ${ }^{79}$. Esta tendencia explotará en el Siglo de Oro con Quevedo y Gracián, con textos ampliamente conocidos (Quevedo, Premática de las cotorreras; Gracián, El Criticón).

Volviendo a Lope, creemos que el significado de estos comentarios debe ser tomado con cautela. De un lado, no debemos confundir las expresiones misóginas puestas en boca de determinados personajes con la opinión del autor, y de otro y más importante, Lope se está haciendo eco de una larga tradición de debates sobre la mujer en que las posturas misóginas y profeministas se ven igualmente representadas con desigual suerte en cada obra particular. Como recuerda Mercedes Roffé:

Con antecedentes esporádicos desde el siglo IV, y tras un primer auge durante el renacimiento carolingio, el debate literario florece en Europa a partir del siglo XII, cuando la disputa se institucionaliza como método de investigación y enseñanza universitaria. Desde entonces, los debates sobre distintos temas proliferan en latín tanto como en lenguas romances, anglosajonas y eslavas ${ }^{80}$.

75. Cf. Montserrat Mochón Castro, «El enigma de la inteligencia en La prueba de los ingenios lopesca ", Signos literarios, julio-septiembre, 2009, 10, p. 107-125.

76. Cf. Simón A. Vosters, «Lope de Vega y las damas doctas », AIH. Actas III, 1968, p. 909-921.

77. Lope de Vega, La dama boba. La moza del cántaro, ed. Rosa Navarro Durán, Barcelona, Planeta, 1989, acto I, p. 13.

78. Ibid., acto III, p. 98.

79. Cf. Ma Soledad Arredondo, «La mirada de Lope sobre la mujer en las Novelas a Marcia Leonarda", en C. Segura Graíño (coord.), Feminismo y misoginia en la literatura española. Fuentes literarias para la Historia de las mujeres, Madrid, Narcea, 2001, p. 81-95.

80. Mercedes Roffé, " Grisel y Mirabella: a la luz del debate medieval », Cincinnati Romance Review, 1995, vol. XIV, p. 9. 
Y así los debates feministas llegan a España en el siglo XV, donde «El debate acabó siendo un juego de entretenimiento cortesano, retórico e insincero $»^{81}$. Dicho debate puede documentarse desde el Grisel y Mirabella de Juan de Flores (1495) y entronca de forma natural en la pastoril, donde frecuentemente se ve mezclado o sustituido por el debate sobre el amor que podemos ver reflejado en obras como La Galatea de Cervantes (IV disputa sobre el amor, II ausencia o desdén) o La Diana enamorada (IV competición entre Sireno y Arsileo " el uno contra y el otro a favor de Cupido "). Desde este punto de vista no nos extrańa contemplar apenas unas páginas antes una defensa de las mujeres en boca de Olimpio:

[...] sin duda es bajeza notable no honrar en todo tiempo aquellas de quien nacimos, que nos criaron y dieron las primeras costumbres, que nos vistieron y sustentaron con su labor y manos, y sin las cuales jamás decimos que nos hallamos contentos, pues no hay donde ellas faltan cosa alegre, ni donde estén alguna que sea triste ${ }^{82}$.

Por otra parte, la caracterización de Celso dentro del reparto de tendencias y temas del grupo de pastores « el que componía epigramas y con curiosos festones los colgaba de los árboles en honor de las musas " ${ }^{83}$, ya nos daba a entender un cierto carácter circunstancial de sus palabras. Se trata, pues, de un empleo funcional de la fábula, al servicio de la urdimbre narrativa y sus juegos expresivos.

El intento cultista de Lope es evidente al dedicar más de la mitad de la fábula a la narración de los mitos tejidos por Palas y Aracne, donde puede desarrollar todo su saber libresco, y resolver el resto de la fábula en cinco estrofas. Se trata de quintillas, metro estrella de la comedia nueva, al igual que el Isidro, metro poco habitual en el desarrollo de las fábulas mitológicas del momento ${ }^{84}$; no obstante, es necesario tener en cuenta también que dicha fábula se encuentra inserta en una obra pastoril. Puesta en boca de Celso (libro II), requerido por Tirsis, la fábula nace de la écfrasis producida al entrar los protagonistas en el templo de Palas, y explicar Celso las pinturas de las paredes, en las que a un lado se encuentran los vicios de los dioses y a otro las victorias (« Parecía que el autor de aquella pintura había querido imitar la contienda de Aragnes y Palas, porque a una parte estaban los vicios de los dioses y a otra las vitorias con que presumió competir con entrambas $\left.{ }^{85} »\right)$.

81. Juan de Flores, La historia de Grisel y Mirabella, ed. facs, versión e intro. de P. Alcázar López y J. A. González Núñez, Granada, Editorial Don Quijote, 1983, p. 39.

82. Lope de Vega, La Arcadia, ed. cit., libro I, p. 97.

83. Ibid., p. 109.

84. Contamos, sin embargo, con el precedente de las fábulas de Píramo y Tisbe y de Acteón de Cristóbal de Castillejo, escritas en dobles quintillas (variedad abab: ccddc) incluidas en sus Obras (Madrid, 1573) pero ya registradas en el ms. 3691 de la BNM (fol. 69r-78r: La fábula de Acteón; fol. 70v-73v: Historia de Píramo y Tisbe). Cf. Cristóbal de Castillejo, Fábulas mitológicas, ed. B. Perinán, Viareggio-Lucca, Mauro Baroni, 1999.

85. Lope de Vega, La Arcadia, ed. cit., p. 152. 
El recurso de la écfrasis es común en Lope, como explica Florence Rayniée ${ }^{86}$ :

L'ekphrasis, très présente dans l'œuvre lopesque, est la description d'une auvre d'art rencontrée ou imaginée par un personnage de la fiction. Il s'agit donc d'une description à un deuxième niveau, représentation d'une représentation : représentation par les mots de ce qui est déjà représenté, au niveau diégétique, par le pinceau ou le ciseau. Nous évoquerons rapidement les sujets traités dans ces æeuvres d'art pour nous concentrer plus longuement sur ce qui nous semble être le point névralgique de l'ekphrasis lopesque : la mise en scène du regard du personnage. En effet, nous chercherons à savoir comment le regard du personnage sert à introduire, à mener et à justifier la description avant de nous interroger, dans un dernier temps, sur les fonctions de ce procédé.

La descripción de las pinturas de las paredes se ve sustituida por la narración en verso de la fábula de Palas y Aracne por Celso. La identificación entre texto y tejido, propiciada por su propio étimo hacía de la écfrasis un recurso de larga tradición ya en nuestro Siglo de Oro ${ }^{87}$. De esta forma, la fábula de Aracne de Lope acaba reducida a un intento cultista de lucimiento poético propio en un contexto circunstancial en el cual hasta los comentarios misóginos forman parte de un juego cortesano estereotipado a esas alturas del siglo XVII. El siglo por excelencia de las fábulas mitológicas sólo conoce una realización poética del mito de Aracne de carácter circunstancial y estereotipado. Sólo los matices grotescos del mito, la transformación en araña, el intento de suicidio de la protagonista, pueden indicar los motivos del escaso cultivo de un mito con tan alto valor metapoético que hoy en día sigue presente en la mente de los creadores.

86. Florence Raynié, “"Faire voir la littérature" : l'ekphrasis dans le roman de Lope de Vega », en Hommage à Francis Cerdan, ed. F. Cazal, Toulouse, CNRS / Université Toulouse Le Mirail, Coll. « Méridienne », 2008, p. 734-743.

87. Cf. A. Egido, "El tejido del texto en la Égloga III de Garcilaso ", en J. Ma Díez Borque y L. Ribot García (ed.), Garcilaso y su época: del amor y la guerra, Madrid, Sociedad Estatal de conmemoraciones culturales S.A., 2003, p. 179-200. 